\title{
Selectivity Boost in Partial Hydrogenation of Acetylene via Atomic Dispersion of Platinum over Ceria
}

Received 00th January 20xx, Accepted 00th January 20xx

DOI: $10.1039 / \times 0 \times x 00000 x$
Olumide Bolarinwa Ayodele, ${ }^{* a}$ Simone Vinati, ${ }^{b, \dagger}$ Emanuele Barborini, ${ }^{\mathrm{b}, \ddagger}$ Loukya Boddapati, ${ }^{a}$ Khalil El Hajraoui, ${ }^{a}$ Jutta Kröhnert, ${ }^{\mathrm{C}}$ Francis Leonard Deepak, ${ }^{\mathrm{a}}$ Annette Trunschke, ${ }^{\mathrm{C}}$ Yury V. Kolen'ko*a

\begin{abstract}
A high-throughput flame spray pyrolysis directly affords lowloading Pt catalyst supported on cerium oxide, which is an excellent material for selective semihydrogenation of $\mathrm{C}_{2} \mathrm{H}_{2}$ at $180^{\circ} \mathrm{C}$, exhibiting nearly complete conversion of $\mathrm{C}_{2} \mathrm{H}_{2}(98.2 \%)$ with high selectivity towards $\mathrm{C}_{2} \mathrm{H}_{4}(\mathbf{8 7 . 1 \% )}$. Pt in this catalyst is atomically dispersed within cerium oxide, and this structural feature restricts $\mathrm{C}_{2} \mathrm{H}_{4}$ adsorption as $\pi$-bonded, known to promote $\mathrm{C}_{2} \mathrm{H}_{4}$ selectivity.
\end{abstract}

Partial hydrogenation of $\mathrm{C}_{2} \mathrm{H}_{2}$ is an important industrial process for converting traces of $\mathrm{C}_{2} \mathrm{H}_{2}$ in the $\mathrm{C}_{2} \mathrm{H}_{4}$ product stream from naphtha cracker to $\mathrm{C}_{2} \mathrm{H}_{4}\left(\mathrm{C}_{2} \mathrm{H}_{2}+\mathrm{H}_{2} \rightarrow \mathrm{C}_{2} \mathrm{H}_{4}\right)$, otherwise $\mathrm{C}_{2} \mathrm{H}_{2}$ will poison the Ziegler-Natta catalyst during olefin polymerization. An industrial catalyst for this reaction is $\mathrm{PdAg} / \mathrm{Al}_{2} \mathrm{O}_{3}$ with typical $\mathrm{Pd}$ weight loadings of $0.03 \%,{ }^{1}$ which unfortunately deactivates with time due to the formation of subsurface $\mathrm{H}$ in the form of $\beta$-PdH hydride and coke build-up on active $\mathrm{Pd}$ sites. ${ }^{2}$ Using smaller Pd clusters and bimetallic systems provides a useful strategy for overcoming these drawbacks. Small Pd sizes shift the metal $d$-band center downward relative to the Fermi level $\left(\mathrm{E}_{\mathrm{F}}\right)$, which weakens the adsorption of $\mathrm{C}_{2} \mathrm{H}_{4}$, and thus facilitates $\mathrm{C}_{2} \mathrm{H}_{4}$ turnover preventing undesired subsequent hydrogenation of $\mathrm{C}_{2} \mathrm{H}_{4}$ to $\mathrm{C}_{2} \mathrm{H}_{6}{ }^{3}$ Alloying of $\mathrm{Pd}$ with metals, such as $\mathrm{Ag}, \mathrm{Ga}, \mathrm{Au}$, $\mathrm{Cu}, \mathrm{Zn}$, renders the active $\mathrm{Pd}$ sites spatially isolated, which prevents coking while increasing the selectivity towards $\mathrm{C}_{2} \mathrm{H}_{4}$ via a site-isolation concept. ${ }^{4}$ Reducing catalyst acidity is another approach to tackle its deactivation (fouling), resulting from the formation of green oil and carbonaceous deposits.

Recently, we embarked on the investigation of catalysts for partial hydrogenation of $\mathrm{C}_{2} \mathrm{H}_{2}$. Initially, we were interested in understanding the behavior of $\mathrm{Pd}$ catalysts using combined

\footnotetext{
a. International Iberian Nanotechnology Laboratory, Braga 4715-330, Portugal.

E-mail: oluayodele@outlook.com,yury.kolenko@inl.int

b. Tethis S.p.A., Milan 20143, Italy.

c. Department of Inorganic Chemistry, Fritz-Haber-Institut der M ax-PlanckGesellschaft, Berlin 14195, Germany.

† Present address: ParteQ GmbH, M alsch 76316, Germany.

¥ Present address: Luxembourg Institute of Science and Technology, Esch-surAlzette 4362, Luxembourg.

Electronic Supplementary Information (ESI) available. See DOI: 10.1039/x0xx00000x
}

experimental-theoretical approach. ${ }^{5}$ The catalyst achieved a high $\mathrm{C}_{2} \mathrm{H}_{2}$ conversion $\mathrm{X}_{\mathrm{C} 2 \mathrm{H} 2} \approx 97 \%$ but a rather poor selectivity towards $\mathrm{C}_{2} \mathrm{H}_{4} \mathrm{~S}_{\mathrm{C} 2 \mathrm{H} 4} \approx 62 \%$. Importantly, there was a qualitative and quantitative match between experimental results and computational modeling. Further, motivated by the reduction of the catalyst's cost while improving its selectivity, we theoretically explored and experimentally realized bimetallic $\mathrm{PtCu}^{6}$ showing high selectivity $\mathrm{S}_{\mathrm{C} 2 \mathrm{H} 4} \approx 85 \%$ at near-complete $\mathrm{X}_{\mathrm{C} 2 \mathrm{H} 2}$. In the present study, we turn our attention to continuously expanding the concept of atomically dispersed catalysts, which show high activity and selectivity owing to the enhanced density and low coordination number of active sites homogeneously distributed through the supporting material. ${ }^{7}$ Herein, we disclose a general approach for scalable preparation of Pt catalyst atomically dispersed over $\mathrm{CeO}_{2}$ support through a high-throughput flame spray pyrolysis (FSP) method.

Notably, the FSP aerosol synthesis of nanostructured materials is a well-established method for the gas-phase production of a wide variety of nanoparticles. ${ }^{8}$ In the FSP, a liquid solution containing the correct stoichiometry of elements of interest (typically in the form of organometallics or nitrates) is sprayed into a flame. Here, the chemicals are pyrolyzed and the contained elements are released in the gas phase to form nanoparticles composed by the same elements. One of the main advantages of FSP is the single-step synthesis of complex nanoparticles without the necessity of post-treatments, such as calcination. ${ }^{9}$ M oreover, in the last decades, FSP was scaled-up to industrial exploitation, becoming a competitive alternative to traditional nanoparticle preparation methods, economically as well as from the environmental point of view. ${ }^{10,11}$

We intended to develop a highly dispersed $\mathrm{Pt} / \mathrm{CeO}_{2}$ catalyst as well as cluster $\mathrm{Pt} / \mathrm{CeO}_{2}$ catalyst and compare their ability to accomplish selective hydrogenation of $\mathrm{C}_{2} \mathrm{H}_{2}$ to $\mathrm{C}_{2} \mathrm{H}_{4}$. For this purpose, two catalysts with low $\mathbf{0 . 2 3} \% \mathrm{Pt} / \mathbf{C e O}_{2}$ and high $5 \% \mathrm{Pt} / \mathrm{CeO}_{2}$ platinum loadings were synthesized by FSP, along with pure $\mathbf{C e O}_{2}$ and $\mathbf{0 . 5} \% \mathrm{Pt} / \mathbf{C e O}_{2}$ for comparison (Fig. S1). A detailed description of synthesis, characterization, and catalytic testing are presented in the ESI. The physicochemical properties 
of the catalysts were systematically studied and correlated with the performance in partial hydrogenation of $\mathrm{C}_{2} \mathrm{H}_{2}$.

We began by studying the catalytic properties of the assynthesized catalysts. It is well known that FSP results in the formation of oxide products due to the oxidative burning principle of the technique, and accordingly, the Pt phase is expected to appear as PtO in the resultant catalysts (Fig. S2). ${ }^{12}$ Hence, for catalytic testing, the materials were first subjected to reduction in $\mathrm{H}_{2}$ / He mixture at the respective temperatures established by $\mathrm{H}_{2}$ temperature-programmed reduction $\left(\mathrm{H}_{2}-\right.$ TPR). To eliminate the possible effect of particle size variation, the temperature $(T)$ was brought to the highest reaction temperature $\left(R_{x} T\right)$ of catalytic testing, and the reaction products were measured as the $T$ ramped down at a programmed rate.

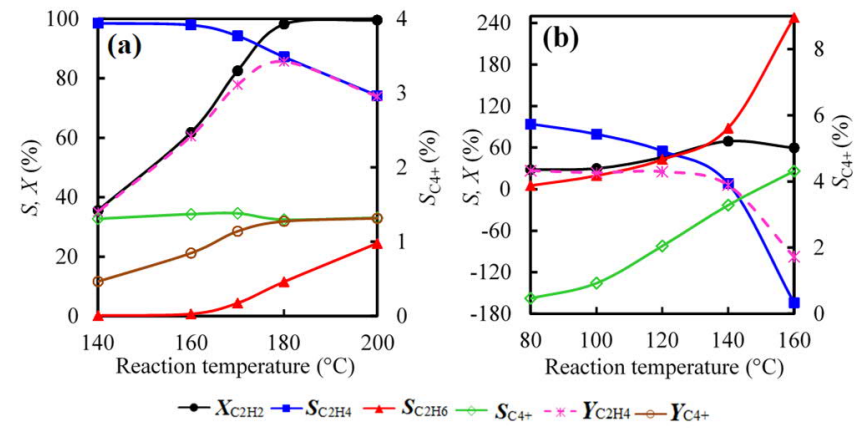

Fig. 1 Catalytic properties of $\mathbf{0 . 2 3} \% \mathrm{Pt} / \mathrm{CeO}_{2}$ (a) and $\mathbf{5} \% \mathrm{Pt} / \mathrm{CeO}_{2}$ (b) catalysts as a function of reaction temperature RxT. Space velocity of $630000 \mathrm{~mL} \mathrm{~g}^{-1} \mathrm{~h}^{-1}$.

The reactor feed composition was close to industrial settings, simulating the gas mixture having the excess of $\mathrm{C}_{2} \mathrm{H}_{4}$ in the stream under atmospheric pressure, viz, 1, 20, 20, $59 \mathrm{~mL} \mathrm{\textrm {min } ^ { - 1 }}$ of $\mathrm{C}_{2} \mathrm{H}_{2}, \mathrm{C}_{2} \mathrm{H}_{4}, \mathrm{H}_{2}$, He, respectively. Figs. $1 \mathrm{a}$, b show conversion (X) of $\mathrm{C}_{2} \mathrm{H}_{2}$, selectivity (S) tow ards $\mathrm{C}_{2} \mathrm{H}_{4}, \mathrm{C}_{2} \mathrm{H}_{6}$, and combined but1-ene plus buta-1,3-diene ( $\mathrm{C} 4+$ ) products and their yields $(\mathrm{Y})$ as a function of RxT. Exploration of catalytic properties of $0.23 \% \mathrm{Pt} / \mathrm{CeO}_{2}$ revealed that $\mathrm{X}_{\mathrm{C} 2 \mathrm{H} 2}$ increases with $\mathrm{RXT}$, while $\mathrm{S}_{\mathrm{C} 2 \mathrm{H} 4}$ reduces, and $\mathrm{S}_{\mathrm{C} 2 \mathrm{H} 6}$ increases at high $\mathrm{R}_{\mathrm{X}} \mathrm{T}$. This is consistent with thermodynamic consideration, wherein full hydrogenation to $\mathrm{C}_{2} \mathrm{H}_{6}$ is favored at higher temperatures $\left(\mathrm{C}_{2} \mathrm{H}_{2}+\mathrm{H}_{2} \rightarrow \mathrm{C}_{2} \mathrm{H}_{4}\right.$, $\left.\Delta \mathrm{H}^{\circ}=-175.4 \mathrm{~kJ} \mathrm{~mol}^{-1} ; \mathrm{C}_{2} \mathrm{H}_{4}+\mathrm{H}_{2} \rightarrow \mathrm{C}_{2} \mathrm{H}_{6}, \Delta \mathrm{H}=-136.9 \mathrm{~kJ} \mathrm{~mol}^{-1}\right)$. The best results for $\mathbf{0 . 2 3} \% \mathrm{Pt} / \mathrm{CeO}_{2}$ were obtained at $180{ }^{\circ} \mathrm{C}$, where the catalyst achieves $\mathrm{X}_{\mathrm{C} 2 \mathrm{H} 2}=98.2 \%$ with excellent $\mathrm{S}_{\mathrm{C} 2 \mathrm{H} 4}=87.1 \%$. Further increase of $\mathrm{R}_{\mathrm{X}} \mathrm{T}$ to industrially-relevant $200{ }^{\circ} \mathrm{C}$ leads to enhanced $\mathrm{X}_{\mathrm{C} 2 \mathrm{H} 2}=99.6 \%$ albeit with $\approx 13 \%$ loss in $\mathrm{S}_{\mathrm{C} 2 \mathrm{H} 4}=74.2 \%$, leading to an increase in $\mathrm{S}_{\mathrm{C} 2 \mathrm{H} 6}$ and $\mathrm{Y}_{\mathrm{C} 4+}$ (Fig. 1a).

On the other hand, the $\mathbf{5} \% \mathrm{Pt} / \mathbf{C e O}_{2}$ catalyst shows a deviating trend in performance (Fig. 1b). As RxT increases, the $\mathrm{X}_{\mathrm{C} 2 \mathrm{H} 2}$ also increases and reaches a maximum at $140{ }^{\circ} \mathrm{C}$ with $\mathrm{X}_{\mathrm{C} 2 \mathrm{H} 2}=70 \%$. At $140{ }^{\circ} \mathrm{C}, \mathrm{S}_{\mathrm{C} 2 \mathrm{H} 4}$, however, drastically reduces to $8.3 \%$, while $\mathrm{S}_{\mathrm{C} 2 \mathrm{H} 6}$ and $\mathrm{S}_{\mathrm{C} 4+}$ increase to $88.4 \%$ and $3.3 \%$, respectively. As the RxT increases further to $160^{\circ} \mathrm{C}, \mathrm{X}_{\mathrm{C} 2 \mathrm{H} 2}$ reduces to $59.6 \%$, while $\mathrm{S}_{\mathrm{C} 2 \mathrm{H} 4}$ dived to $-163.7 \%$, and both $\mathrm{S}_{\mathrm{C} 2 \mathrm{H} 6}$ and $\mathrm{S}_{\mathrm{C}_{4}+}$ increased to $248.1 \%$ and $4.3 \%$, respectively. The negative $\mathrm{S}_{\mathrm{C} 2 \mathrm{H} 4}$ and $\mathrm{S}_{\mathrm{C} 2 \mathrm{H} 6}>100 \%$ imply that both $\mathrm{C}_{2} \mathrm{H}_{2}$ and substantive amounts of co-fed $\mathrm{C}_{2} \mathrm{H}_{4}$ underwent full hydrogenation to $\mathrm{C}_{2} \mathrm{H}_{6}$. Notably, in the absence of Pt, pure $\mathrm{CeO}_{2}$ was found to be inactive for $\mathrm{C}_{2} \mathrm{H}_{2}$ hydrogenation in all $R_{x} T$ tested $\left(80-200^{\circ} \mathrm{C}\right)$.
The above catalytic results unambiguously demonstrate that our newly developed $\mathbf{0 . 2 3} \% \mathrm{Pt} / \mathbf{C e O}_{2}$ significantly outperforms $5 \% \mathrm{Pt} / \mathrm{CeO}_{2}$ in terms of desired $\mathrm{C}_{2} \mathrm{H}_{4}$ product yield, providing maximum $\mathrm{Y}_{\mathrm{C} 2 \mathrm{H} 4}=85.5 \%$ at $180{ }^{\circ} \mathrm{C}$ with stable activity and selectivity after the time-on-stream (TOS) testing for at least $10 \mathrm{~h}$ (Fig. S3). M oreover, this high-performing catalyst contains $>20$ times less amount of Pt, which also plays a positive role in the development of cost-effective catalytic materials. Similarly, when compared with some selected state-of-the-art catalysts, including the industrial $\mathrm{PdAg}$ catalyst, $\mathbf{0 . 2 3} \% \mathrm{Pt} / \mathrm{CeO}_{2}$ obviously outperformed them, especially when the amount of active metal loading, $\mathrm{Rx}_{\mathrm{T}} \mathrm{T}$, and space velocity is considered (Table S1). ${ }^{4}$ 6, 13-20 Therefore, we were interested in understanding the reasons behind the excellent activity and selectivity of $0.23 \% \mathrm{Pt} / \mathrm{CeO}_{2}$ as compared to $5 \% \mathrm{Pt} / \mathrm{CeO}_{2}$.

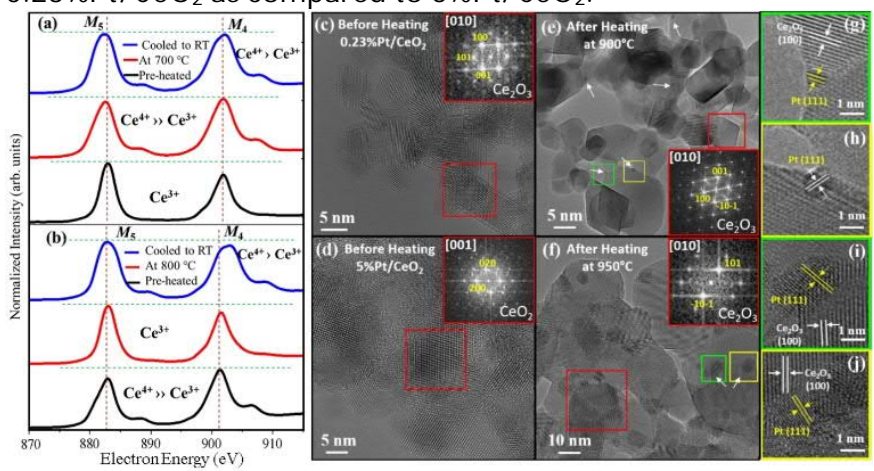

Fig. 2 EELS spectra of Ce- $\mathrm{M}_{4,5}$ edges for $\mathbf{0 . 2 3} \% \mathrm{Pt} / \mathbf{C e O}_{2}$ (a) and $\mathbf{5} \% \mathrm{Pt} / \mathbf{C e O}_{2}$ (b) acquired at different experimental conditions: before, during, and after heat treatment, as indicated in the legends. The oxidation states are predicted from $\mathrm{Ce}-\mathrm{M}_{4,5}$ line ratios, as well as from the spectral shapes. (c) and (d) are HRTEM images and the corresponding Fast Fourier Transforms (FFTs) for $\mathbf{0 . 2 3} \% \mathrm{Pt} / \mathrm{CeO}_{2}$ and $\mathbf{5} \% \mathrm{Pt} / \mathrm{CeO}_{2}$ sample before heating, while (e) and (f) are their respective HRTEM images and FFTs after heating. (g) and (h) are the zoom-in images of Pt nanoclusters (marked with white arrows in (e)) appearing after heating. (i) and (j) are the zoom-in images of a Pt nanocluster (marked with a white arrow in (f)) appearing after heating.

To this end, we employed in situ non-isothermal electron energy-loss spectroscopy (EELS), which can simultaneously investigate both electronic and structural properties. The $\mathrm{M}_{5} / \mathrm{M}_{4}$ intensity ratios, the spectral features, and broadening parameters have been identified to be sensitive to the chemical state of $\mathrm{Ce}$, and the oxidation state can be determined such that $\mathrm{M}_{5}>\mathrm{M}_{4}$ indicates $\mathrm{Ce}^{3+}$ oxidation state and vice versa. ${ }^{21}$ According to the EELS analysis, the predominant Ce oxidation states were found to be $3+$ and $4+$ in $0.23 \% \mathrm{Pt} / \mathrm{CeO}_{2}$ and $5 \% \mathrm{Pt} / \mathrm{CeO}_{2}$, respectively (Figs. $2 \mathrm{a}, \mathrm{b}$ ). This result was further corroborated by high-resolution transition electron microscopy (HRTEM), which confirms the presence of $\mathrm{Ce}_{2} \mathrm{O}_{3}$ in $\mathbf{0 . 2 3} \% \mathrm{Pt} / \mathbf{C e O}_{2}$ and $\mathrm{CeO}_{2}$ in $\mathbf{5 \%} \mathbf{P t} / \mathbf{C e O}_{2}$ (Figs. $2 \mathrm{c}$,d). These results showed that the low Pt loading caused obvious defects in the support structure leading to higher concentrations of $\mathrm{Ce}^{3+}$ and a large number of $O$ vacancies.

Interestingly, in our intensive studies of $\mathbf{0 . 2 3} \% \mathrm{Pt} / \mathbf{C e O}_{2}$ by HRTEM, high-angle annular dark-field scanning transmission electron microscopy (HAADF-STEM), and energy-dispersive $X$ ray spectroscopy (STEM -EDX), no evidence of Pt being present in the as-synthesized catalyst was found (Figs. 2c, 3a). We 
hypothesized that if Pt exists in the sample, as suggested by catalytic results, they would appear at high temperatures due

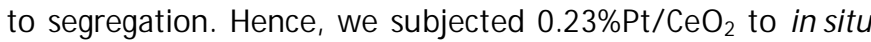
TEM heating experiment (to $900{ }^{\circ} \mathrm{C}$, Video S1), and in fact, the experiment shows the evolution of Pt at $900{ }^{\circ} \mathrm{C}$ (Figs. 2e, 3b). The following electron microscopy analysis of the heated $0.23 \% \mathrm{Pt} / \mathrm{CeO}_{2}$ confirms the formation of small $1-2 \mathrm{~nm} \mathrm{Pt}$ clusters as a result of Pt segregation at $\mathrm{T} \geq 800^{\circ} \mathrm{C}$ (Figs. 2e,g, h, 3b). We also conducted similar experiments for the catalyst with $5 \%$ Pt loading. Unlike $\mathbf{0 . 2 3} \% \mathrm{Pt} / \mathbf{C e O}_{2}$, the scarce presence of small Pt clusters was already observed in the as-synthesized $\mathbf{5} \% \mathrm{Pt} / \mathrm{CeO}_{2}$ (Fig. $3 \mathrm{C}$ ). M oreover, the in situ TEM heating analysis of the sample shows a significant growth of the Pt clusters with an increase in temperature, leading to the formation of 3-6 nm clusters after heating to $900^{\circ} \mathrm{C}$ (Video S2, Figs. 2f,i,j, 3d).

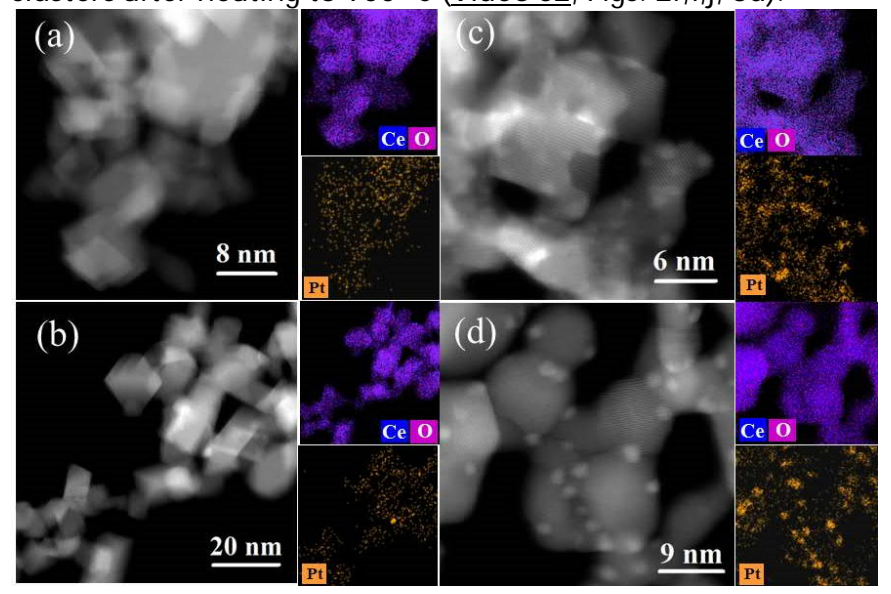

Fig. 3 HAADF-STEM images of $\mathbf{0 . 2 3} \% \mathrm{Pt} / \mathrm{CeO}_{2}(\mathrm{a}, \mathrm{b})$ and $\mathbf{5} \% \mathrm{Pt} / \mathrm{CeO}_{2}(\mathrm{c}, \mathrm{d})$ catalysts before $(a, c)$ and after $(b, d)$ in situ TEM heating experiment to $900{ }^{\circ} \mathrm{C}$, together with the corresponding STEM-EDX elemental maps for Pt and Ce/ 0 mixture.

The variation of the Pt cluster sizes also reflected in the samples' textural properties (Fig. S4, Table S2). The pore structure of the samples showed that the FSP synthesis leads to the formation of mesoporous Ce oxide. Whereas $\mathbf{0 . 2 3} \% \mathrm{Pt} / \mathrm{CeO}_{2}$ demonstrates no significant variation in textural properties as compared to the pure $\mathrm{CeO}_{2}$ control, $\mathbf{5} \% \mathrm{Pt} / \mathbf{C e O}_{2}$ shows a slight increase in textural properties, most likely due to the contribution from the presence of Pt nanoclusters.

The electron microscopy investigation suggests that there is a unique conceptual difference between $\mathbf{0 . 2 3} \% \mathrm{Pt} / \mathbf{C e O}_{2}$ and $5 \% \mathrm{Pt} / \mathrm{CeO}_{2}$ catalysts where the catalysts with $5 \% \mathrm{Pt}$ loading is, at least in part, Pt nanoclusters supported on cerium(iv) oxide, i.e. $\mathrm{CeO}_{2}$. On the other hand, the $0.23 \%$ Pt loading most likely leads to the formation of highly dispersed Pt over $\mathrm{Ce}_{2} \mathrm{O}_{3}$, perhaps in the form of single-atom or a solid solution. Therefore, we investigated whether dispersed and clustered Pt interacts with cerium oxide support differently using $\mathrm{H}_{2}$-TPR (Fig. 4a). We found that pure $\mathrm{CeO}_{2}$ control shows two peaks at 486 and $873{ }^{\circ} \mathrm{C}$, which reflect the reduction of the surface $\left(\mathrm{O}_{\mathrm{S}}\right)$ and bulk $\left(\mathrm{O}_{\mathrm{B}}\right)$ lattice oxygen. ${ }^{22}$ The $\mathrm{O}_{\mathrm{B}}$ peak appears unperturbed for all three samples. In contrast, $\mathrm{O}_{\mathrm{s}}$ peaks of the Pt catalysts shift towards lower reduction temperatures due to Pt interaction with the oxide support via a somewhat Mars-van Krevelen-like mechanism. While the PtO reduction peak of
$5 \% \mathrm{Pt} / \mathrm{CeO}_{2}$ is well-separated from its $\mathrm{O}_{\mathrm{s}}$ peak, the PtO and $\mathrm{O}_{\mathrm{s}}$ peaks of $\mathbf{0 . 2 3} \% \mathrm{Pt} / \mathrm{CeO}_{2}$ were found to be conjugated, highlighting strong metal-support interaction (SMSI) in the catalyst. ${ }^{23}$ M oreover, X-ray photoelectron spectroscopy (XPS) analysis of the catalysts indicates that the binding energy $(B E)$ of Pt $4 \mathrm{f}$, usually seen at $72.4 \mathrm{eV}$, shifted to a lower BE of $72.1 \mathrm{eV}$ in $\mathbf{5 \%} \mathrm{Pt} / \mathbf{C e O}_{2}$ and a higher $\mathrm{BE}$ of $72.6 \mathrm{eV}$ in $\mathbf{0 . 2 3} \% \mathrm{Pt} / \mathbf{C e O}_{\mathbf{2}}$ (Fig. 4b). Although the observed $+0.20 \mathrm{eV}$ shift for $0.23 \% \mathrm{Pt} / \mathrm{CeO}_{2}$ is rather small and could be affected by other contributions, such as band bending and final state effects, we believe that this shift is a confirmation of SMSI in the catalyst due to combined electronic modulation. ${ }^{24}$
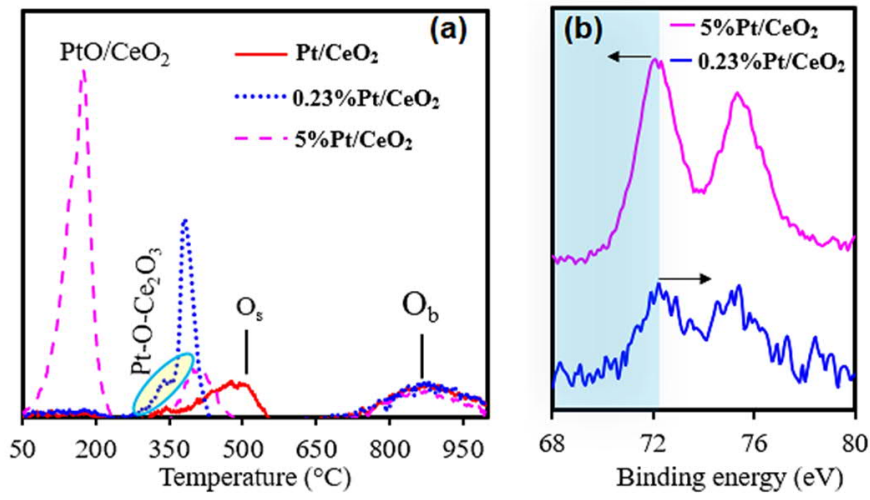

Fig. 4 (a) Comparison of $\mathrm{H}_{2}$-TPR behavior of control pure $\mathrm{CeO}_{2}$ support as well as $0.23 \% \mathrm{Pt} / \mathrm{CeO}_{2}$ and $\mathbf{5} \% \mathrm{Pt} / \mathrm{CeO}_{2}$ catalysts. (b) Comparison of XPS narrow scans of the Pt $4 \mathrm{f}$ region for $\mathbf{0 . 2 3} \% \mathrm{Pt} / \mathrm{CeO}_{2}$ and $\mathbf{5} \% \mathrm{Pt} / \mathrm{CeO}_{2}$.
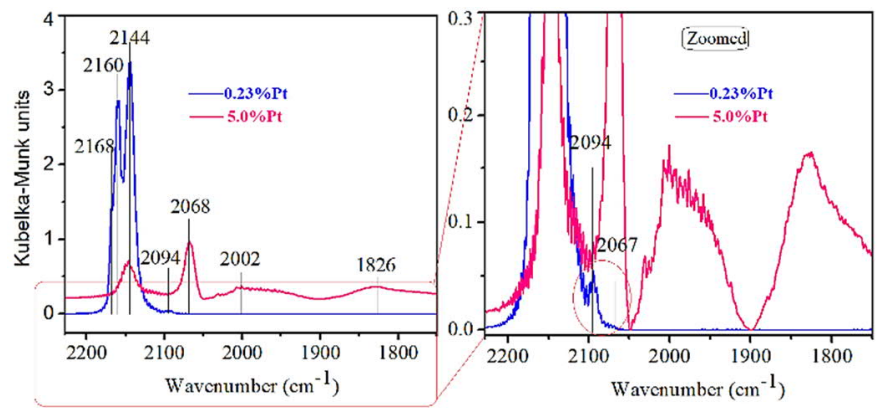

Fig. 5 Comparison of DRIFT spectra of $\mathrm{CO}$ adsorption over $\mathbf{0 . 2 3} \% \mathrm{Pt} / \mathrm{CeO}_{2}$ and $\mathbf{5} \% \mathrm{Pt} / \mathrm{CeO}_{2}$ catalysts.

The above results indicate that the high-performing $0.23 \% \mathrm{Pt} / \mathrm{CeO}_{2}$ catalyst exhibits dispersed Pt strongly interacting with cerium oxide. Pt in this catalyst is likely to be either confined within cerium oxide or atomically dispersed, influencing the binding of the reactive molecules differently. Therefore, we subjected the catalysts (after reduction in $\mathrm{H}_{2} / \mathrm{He}$ ) to $\mathrm{CO}$ adsorption using diffuse reflectance infrared Fourier transform (DRIFT) spectroscopy, and the results are plotted in Fig. 5. The peaks observed at higher wavenumbers, 2168, 2160, and $2144 \mathrm{~cm}^{-1}$, are ascribed to $\mathrm{CO}$ adsorbed on $\mathrm{Ce}^{\mathrm{n}+}, \mathrm{CO}$ in contact with $\mathrm{OH}$ groups, and physisorbed $\mathrm{CO}$, respectively. ${ }^{25} \mathrm{We}$ found that $5 \% \mathrm{Pt} / \mathrm{CeO}_{2}$ adsorbed $\mathrm{CO}$ at 2068, 1950, and $1837 \mathrm{~cm}^{-1}$, which are due to linear, isolated bridged, and tricoordinated bonds. ${ }^{26}$ This result demonstrates that $5 \% \mathrm{Pt} / \mathbf{C e O}_{2}$ is characterized by the presence of Pt in form of clusters with 
varying sizes, and it is consistent with our electron microscopy study. In sharp contrast, $\mathbf{0 . 2 3} \% \mathrm{Pt} / \mathbf{C e O}_{2}$ demonstrates only one type of CO adsorption over Pt species at $2094 \mathrm{~cm}^{-1}$, which is associated with the presence of a significant density of atomically dispersed $\mathrm{Pt} \delta+$ in the catalyst. 25,27

To gain deeper understanding of the $\mathrm{CO}$ adsorption over different $\mathrm{Pt}$ species, another $\mathrm{CeO}_{2}$-supported catalyst with $0.5 \% \mathrm{Pt}$ loading $\left(\mathbf{0 . 5} \% \mathrm{Pt} / \mathrm{CeO}_{2}\right)$ was synthesized and studied. On the one hand, the DRIFT spectroscopy demonstrates that as the Pt loading increased from $0.23 \%$ to $0.5 \%$, the resultant $\mathbf{0 . 5} \% \mathrm{Pt} / \mathrm{CeO}_{2}$ catalyst is still characterized by only one type of $\mathrm{CO}$ adsorption (Fig. S5). On the other hand, the CO adsorption peak slightly shifts to lower wavenumber of $2067 \mathrm{~cm}^{-1}$, which has been attributed to the presence of Pt sub-nanometre clusters, ${ }^{28}$ and not to atomically dispersed Pt.

The catalytic activity study shows that $\mathbf{0 . 5 \%} \mathrm{Pt} / \mathbf{C e O}_{2}$ achieves near-complete $\mathrm{X}_{\mathrm{C} 2 \mathrm{H} 2}$ of $98.3 \%$ at $180{ }^{\circ} \mathrm{C}$, which is similar to the $\mathbf{0 . 2 3} \% \mathrm{Pt} / \mathbf{C e O}_{2}$, while the $\mathrm{S}_{\mathrm{C} 2 \mathrm{H} 4}, \mathrm{~S}_{\mathrm{C} 2 \mathrm{H} 6}$ and $\mathrm{S}_{\mathrm{C} 4+}$ over $\mathbf{0 . 5} \% \mathrm{Pt} / \mathbf{C e O}_{2}$ appear to be somewhat in-between atomically dispersed $\mathbf{0 . 2 3} \% \mathrm{Pt} / \mathrm{CeO}_{2}$ and cluster $\mathbf{5 \%} \mathrm{Pt} / \mathbf{C e O}_{2}$ catalysts (Fig. S6). M oreover, $\mathbf{0 . 5} \% \mathrm{Pt} / \mathbf{C e O}_{2}$ provides the maximum $\mathrm{Y}_{\mathrm{C} 2 \mathrm{H} 4}$ of $55.8 \%$ at $150{ }^{\circ} \mathrm{C}$, which is barely $10{ }^{\circ} \mathrm{C}$ higher than what was observed over cluster $\mathbf{5} \% \mathrm{Pt} / \mathrm{CeO}_{2}$ catalyst (Fig. $1 \mathrm{~b}$ ). This trend suggests that $\mathbf{0 . 5} \% \mathrm{Pt} / \mathrm{CeO}_{2}$ exhibits a significant structural similarity with the $5 \% \mathrm{Pt} / \mathrm{CeO}_{2}$ catalyst rather than with atomically dispersed $0.23 \% \mathrm{Pt} / \mathrm{CeO}_{2}$ material.

Apparently, there is significant variation in the structural and electronic properties between atomically dispersed and nanocluster Pt catalysts, and this structural specificity of the catalyst governs the observed catalytic performance. Specifically, three modes for $\mathrm{C}_{2} \mathrm{H}_{4}$ adsorption over catalyst have been reported: $\pi$-bonded, di- $\sigma$-bonded, and ethylidyne. Ethylidyne species exhibit the highest initial adsorption heat (185 kJ mol-1) resulting from the dissociation adsorption of $\mathrm{C}_{2} \mathrm{H}_{4}$ on the 3-fold adjacent metal atoms, which easily induces the over-hydrogenation of acetylene to ethane. ${ }^{29}$ Based on our results, one can deduce that atomic dispersion of $\mathrm{Pt}$ in $\mathbf{0 . 2 3} \% \mathrm{Pt} / \mathrm{CeO}_{2}$ restricts excessive $\mathrm{C}_{2} \mathrm{H}_{4}$ adsorption, thus clearly demonstrating the importance of $\pi$-bonded configuration in achieving selectivity towards desired $\mathrm{C}_{2} \mathrm{H}_{4}$ product (Fig. 1a). Importantly, this observation is in good agreement with the previously reported literature on AgPd, AuPd, CuPt bimetallic6, 30,31 , and Pt single atom ${ }^{28}$ catalysts. On the other hand, in $5 \% \mathrm{Pt} / \mathrm{CeO}_{2}$ catalyst larger sizes of Pt clusters with varying size distribution is responsible for multi- $\sigma$ bonding of $\mathrm{C}_{2} \mathrm{H}_{4}$, thus inducing the undesired increase in the $\mathrm{S}_{\mathrm{C} 2 \mathrm{H}}$ and $\mathrm{S}_{\mathrm{C} 4+}$ especially as the temperature increases (Fig. 1b). 32

In conclusion, high-throughput flame spray pyrolysis is a viable method for the synthesis of either nanocluster or atomically dispersed Pt catalysts supported on cerium oxide. In partial hydrogenation of $\mathrm{C}_{2} \mathrm{H}_{2}$ to $\mathrm{C}_{2} \mathrm{H}_{4}$ at $180{ }^{\circ} \mathrm{C}$, the new atomically dispersed $\mathbf{0 . 2 3} \% \mathbf{P t} / \mathbf{C e O}_{2}$ catalyst is stable and achieves nearly full conversion of $98.2 \%$ delivering high selectivity of $87.1 \%$. Notably, this catalyst significantly outperforms the $5 \% \mathrm{Pt} / \mathrm{CeO}_{2}$ nanocluster catalyst that is prone to undesired full hydrogenation of $\mathrm{C}_{2} \mathrm{H}_{2}$ to $\mathrm{C}_{2} \mathrm{H}_{6}$. Atomic dispersion of Pt over cerium oxide favors weak $\pi$-bonded adsorption of $\mathrm{C}_{2} \mathrm{H}_{4}$ over the catalyst. In turn, weak bonding facilitates the release of $\mathrm{C}_{2} \mathrm{H}_{4}$ providing high selectivity towards this product. Overall, we have shown how activity and selectivity of the hydrogenation catalyst can be boosted by atomic dispersion of the active Pt metal while the catalyst cost can be markedly reduced by lowering the mass loading of this rare and expensive element.

\section{Conflicts of interest}

There are no conflicts to declare.

\section{Acknowledgments}

We thank the members of the Nanochemistry Research Group (http://nanochemgroup.org) at INL for valuable discussions. This work was partially supported by the EU's Horizon 2020 research and innovation program through the CritCat Project under Grant Agreement No. 686053. L.B. acknowledges the EU's Horizon 2020 MSCA COFUND program through the NanoTRAINforGrowth II project.

\section{Notes and references}

1. A. N. R. Bos, E. S. Botsma, F. Foeth, H. W. J. Sleyster and K. R. Westerterp, Chemical Engineering and Processing: Process Intensification, 1993, 32, 53-63.

2. A. Borodzinski, Catal Lett, 1999, 63, 35-42.

3. H. Xin, A. Vojvodic, J. Voss, J. K. Nørskov and F. AbildPedersen, Physical Review B, 2014, 89, 115114.

4. M. Armbrüster, K. Kovnir, M. Behrens, D. Teschner, Y. Grin and R. Schlögl, Journal of the American Chemical Society, 2010, 132, 14745-14747.

5. L. P. L. Gonçalves, J. Wang, S. Vinati, E. Barborini, X.-K. Wei, M. Heggen, M. Franco, J. P. S. Sousa, D. Y. Petrovykh, O. S. G. P. Soares, K. Kovnir, J. Akola and Y. V. Kolen'ko, International Journal of Hydrogen Energy, 2020, 45, 12831296.

6. O. B. Ayodele, R. Cai, J. Wang, Y. Ziouani, Z. Liang, M. C. Spadaro, K. Kovnir, J. Arbiol, J. Akola, R. E. Palmer and Y. V. Kolen'ko, ACS Catalysis, 2020, 10, 451-457.

7. R. T. Hannagan, G. Giannakakis, M. FlytzaniStephanopoulos and E. C. H. Sykes, Chemical Reviews, 2020, DOI: 10.1021/acs.chemrev.0c00078.

8. S. Li, Y. Ren, P. Biswas and S. D. Tse, Progress in Energy and Combustion Science, 2016, 55, 1-59.

9. W. Y. Teoh, R. Amal and L. M ädler, Nanoscale, 2010, 2, 1324-1347.

10. A. J. Gröhn, S. E. Pratsinis, A. Sánchez-Ferrer, R. M ezzenga and K. Wegner, Industrial \& Engineering Chemistry Research, 2014, 53, 10734-10742.

11. K. Wegner, B. Schimmoeller, B. Thiebaut, C. Fernandez and T. Rao, KONA Powder and Particle Journal, 2011, 29, 251-265.

12. R. Strobel, A. Baiker and S. E. Pratsinis, Advanced Powder Technology, 2006, 17, 457-480.

13. Y. Chen and J. Chen, Applied Surface Science, 2016, 387, 16-27.

14. Y. Liu, J. Zhao, Y. He, J. Feng, T. Wu and D. Li, Journal of Catalysis, 2017, 348, 135-145. 
15. Y. N. Liu, J. T. Feng, Y. F. He, J. H. Sun and D. Q. Li, Catalysis Science \& Technology, 2015, 5, 1231-1240.

16. A. J. McCue, A. Guerrero-Ruiz, C. Ramirez-Barria, I. Rodríguez-Ramos and J. A. Anderson, Journal of Catalysis, 2017, 355, 40-52.

17. G. X. Pei, X. Y. Liu, A. Wang, A. F. Lee, M. A. Isaacs, L. Li, X. Pan, X. Yang, X. Wang, Z. Tai, K. Wilson and T. Zhang, ACS Catalysis, 2015, 5, 3717-3725.

18. G. X. Pei, X. Y. Liu, X. Yang, L. Zhang, A. Wang, L. Li, H. Wang, X. Wang and T. Zhang, ACS Catalysis, 2017, 7, 1491-1500.

19. S. Zhang, C.-Y. Chen, B. W. L. Jang and A.-M. Zhu, Catalysis Today, 2015, 256, 161-169.

20. H. Zhou, X. Yang, L. Li, X. Liu, Y. Huang, X. Pan, A. Wang, J. $L i$ and T. Zhang, ACS Catalysis, 2016, 6, 1054-1061.

21. H. B. Vasili, B. Casals, R. Cichelero, F. M acià, J. Geshev, P. Gargiani, M. Valvidares, J. Herrero-M artin, E. Pellegrin, J. Fontcuberta and G. Herranz, Physical Review B, 2017, 96, 014433.

22. D. He, D. Chen, H. Hao, J. Yu, J. Liu, J. Lu, F. Liu, G. Wan, S. He and Y. Luo, Applied Surface Science, 2016, 390, 959967.

23. X. I. Pereira-Hernández, A. DeLaRiva, V. M uravev, D. Kunwar, H. Xiong, B. Sudduth, M. Engelhard, L. Kovarik, E. J. M. Hensen, Y. Wang and A. K. Datye, Nature Communications, 2019, 10, 1358.

24. T. W. van Deelen, C. Hernández M ejía and K. P. de Jong, Nature Catalysis, 2019, 2, 955-970.

25. M. Kottwitz, Y. Li, R. M. Palomino, Z Liu, G. Wang, Q. Wu, J. Huang, J. Timoshenko, S. D. Senanayake, M.

Balasubramanian, D. Lu, R. G. Nuzzo and A. I. Frenkel, ACS Catalysis, 2019, 9, 8738-8748.

26. J. H. Kang, E. W. Shin, W. J. Kim, J. D. Park and S. H. Moon, Journal of Catalysis, 2002, 208, 310-320.

27. J. Resasco, L. DeRita, S. Dai, J. P. Chada, M. Xu, X. Yan, J. Finzel, S. Hanukovich, A. S. Hoffman, G. W. Graham, S. R. Bare, X. Pan and P. Christopher, Journal of the American Chemical Society, 2020, 142, 169-184.

28. C.-T. Kuo, Y. Lu, L. Kovarik, M. Engelhard and A. M. Karim, ACS Catalysis, 2019, 9, 11030-11041.

29. L. Xu, E. E. Stangland and M. Mavrikakis, Journal of Catalysis, 2018, 362, 18-24.

30. Y. Zhang, W. Diao, J. R. M onnier and C. T. Williams, Catalysis Science \& Technology, 2015, 5, 4123-4132.

31. Y. Zhang, W. Diao, C. T. Williams and J. R. M onnier, Applied Catalysis A: General, 2014, 469, 419-426.

32. A. Zecchina, E. Groppo and S. Bordiga, Chemistry - A European Journal, 2007, 13, 2440-2460. 